\title{
Community Asset Inquiry: A Model for ESOL Teacher Praxis in Family and Community Engagement
}

Excelsior: Leadership in

Teaching and Learning 2019, Vol. 12(2) 115-132

(C) The Author 2020

CC-BY 4.0 International Reprints and permissions: surface.syr.edu/excelsior https://doi.org/10.14305/jn.1

9440413.2020.12.2.02 nyacte.org LNYACTE

\section{Felice Atesoglu Russell ${ }^{1}$ and Amanda Richey ${ }^{2}$}

\begin{abstract}
In this article, we present findings from our qualitative, self-study research on the development and implementation of two course assignments (community asset maps and oral histories) designed to support practicing teachers' praxis in working with English learner (EL) students within the context of family and community engagement. Providing an example of how English to Speakers of Other Languages (ESOL) teacher praxis might be developed, findings are framed by our Community Asset Inquiry model. This model, grounded in equity literacy and transformative family and community engagement supports teachers' development of praxis in support of an asset-based approach, deep knowledge of school communities, critical understanding of the local/global issues that impact those communities, and ways to advocate for EL students and families that leverage strengths, assets, and knowledges. This research addresses the following questions: How does the Community Asset Inquiry model support our work as teacher educators committed to equity and social justice for EL students? How does the Community Asset Inquiry model support M.Ed. TESOL teacher candidates' praxis in working with EL students within the context of family and community engagement? Implications for ESOL teacher education, in particular in online settings, and application of the Community Asset Inquiry model are discussed.

\section{Keywords}

English learners, Praxis, Advocacy, Equity Literacy, Family and Community Engagement

\footnotetext{
${ }^{1}$ Central Connecticut State University

2 Kennesaw State University

Corresponding Author:

Felice Atesoglu Russell, Central Connecticut State University, Department of Educational Leadership, Poliycy \& Instructional technology, School of Education \& Professional Studies, Carroll Hall, Office 340, 1615 Stanley Street, New Britain, CT 05060

Email: frussell@ccsu.edu
} 
How do teachers learn to position themselves as advocates for P-12 English learner (EL) students in the U.S.? We know it is critical that students in a Master of Education (M.Ed.) in Teaching English to Speakers of Other Languages (TESOL) program have guidance and support as they develop a teaching practice that includes a focus on student, family, and community assets and strengths (Russell \& Richey, 2017). Many teachers come to the profession unprepared to draw on the strengths and assets that culturally and linguistically diverse students bring to school (Elfers, Lucero, Stritikus, \& Knapp, 2013; Gandara, Maxwell-Jolly, \& Driscoll, 2005). A goal as teacher educators in a fully online M.Ed. program in TESOL is to support teacher candidates to form an advocacy-stance for EL students. This is accomplished through a focus on the development of equity literacy (Gorski \& Swalwell, 2015; Gorski, 2014; Gorski, 2016) and supporting students as they make connections between theory and practice in effect, praxis (Garton \& Edge, 2012). To understand this intersection, in this paper we examine the implementation of specific course assignments in a M.Ed. TESOL program designed to engage teachers in praxis.

Through a presentation of findings from our self-study research, we propose our Community Asset Inquiry model as a framework for supporting transformational teacher learning. We argue that the Community Asset Inquiry model can be used to develop and support English to Speakers of Other Languages (ESOL) teacher praxis in support of EL students, families, and their communities. Our guiding framework for the M.Ed. TESOL program is framed by aspects of teacher reflective practice, along with teacher expertise, knowledge, and capacity for inclusive practices for EL students. As teacher educators in a M.Ed. TESOL program committed to equity and social justice for EL students, we wanted to understand how the Community Asset Inquiry model could undergird our work.

Additionally, we were interested in how the Community Asset Inquiry model could inform how teacher candidates in the program develop the capacity for praxis in support of EL students, families, and communities. Thus, our analysis in this article focuses on the following questions:

- How does the Community Asset Inquiry model support our work as teacher educators committed to equity and social justice for EL students?

- How does the Community Asset Inquiry model support M.Ed. TESOL teacher candidates' praxis in working with EL students within the context of family and community engagement?

\section{Background}

In this section we provide an overview of our theoretical framework and the relevant constructs that support the Community Asset Inquiry model as developed through a specific graduate-level TESOL course at our university. We draw from the overlapping theoretical frameworks of critical pedagogy and equity-based approaches (Shor, 1992), asset-based teaching models (DiGiacomo \& Gutiérrez, 2017), culturally relevant (Ladson-Billings, 1995) and sustaining pedagogy (Paris, 2012), funds of knowledge (Moll, Amanti, Neff, \& Gonzalez), and family and community engagement (Allen, 2007; Epstein, 2010) as a framework for our online M.Ed. TESOL program (see Appendix A). Graduate students in this program use their own professional context and classrooms as sites for inquiry, curriculum, and pedagogical practice and growth as they move through the program. A major advantage of this approach is that students utilize local teaching contexts for their assessments/assignments in real time as they progress through the program, effectively tracking their own engagement as teachers, researchers, and advocates that engage in praxis. While our students tend to be clustered in local school districts, the online format of the program allows for an accessible graduate program for students in more distant 
locations, including internationally. Asking students to take a contextualizing, grounded approach positions them to transform their engagement in real school communities (Zeichner, 2010) and build critically reflective praxis (Garton \& Edge, 2012) in real time. This facet of engaging locally with real school communities for the purposes of teacher learning and education, aligns with current models of preparing teachers to engage with communities as a transformative learning experience (Zeichner, 2010; Zeichner, Payne, \& Brayko, 2015), as well as adds to the literature by focusing on practicing teachers that are already teaching and working in schools. Moreover, our theoretical framework posits that family and community engagement are essential components for the successful development of collaborative skills, knowledge and attitudes necessary for the creation of and advocacy for inclusive classroom communities. Collaboration and engagement are broadly defined and include understanding diverse families and communities in sociopolitical and global context, communicating effectively and compassionately with families, building relationships with families and community members, and advocating for learners and their families (Epstein, 2011; Lawrence-Lightfoot, 2003).

For this study, two cohorts of graduate students in our online M.Ed. program utilized the theoretical framework and completed two major assignments as the foundation for their work as community-andschool advocates - the community asset map and the oral history project. These two major assignments allowed students to start to paint an asset-rich portrait of their school communities as they envisioned their roles as leaders and advocates for linguistically and culturally diverse learners and families (see Russell \& Richey, 2017). We encouraged students to use the lens of appreciative inquiry (Cooperrider \& Whitney, 2005) as it had the potential to shift their methodology from one of searching for deficits to one that allows for discovering strengths. The appreciative inquiry model (Cooperrider \& Whitney, 2005) provides the theoretical and methodological framing for students' engagement in their school communities (often in schools where they have taught for several years) with the aim of transforming their epistemologies, inclusive practices, and modeling of multimodal literacy practices and representation. Readings for the course included: The Essential Conversation: What Parents and Teachers Can Learn from Each Other (Lawrence-Lightfoot, 2003), Creating Welcoming Schools: A Practical Guide to Home-School Partnerships with Diverse Families (Allen, 2007), and a series of articles and other resources that supported students' engagement with theory and scholarly, assetfocused approaches to school-community relationships. Additionally, our students engaged in weekly critical and reflective discussion spaces online where they were expected to interrogate some of their taken for granted notions about families and communities. It should be noted that this particular course was positioned after students had completed coursework on culture and diversity, critical pedagogy, and several courses on language and literacy.

\section{Praxis, Equity Literacy, Transformational Community Engagement: A Framework for Advocacy}

This research draws on three main theoretical concepts: praxis (Garton \& Edge, 2012), equity literacy (Gorski \& Swalwell, 2015; Gorski, 2014; Gorski, 2016), and transformative community engagement in teacher education (Zeichner, 2010; Zeichner, Payne, \& Brayko, 2015). Praxis in language education to support online learners in TESOL programs is not just about "applying" theory. Praxis is engagement in theorizing in local contexts. This self-study presumes praxis for both the teacher educators involved in this research of their own practice, as well as praxis for the M.Ed. students that are emerging TESOL teacher leaders. By inviting students to engage authentically with their communities, make connections 
to theory, and reflect on the dynamic interplay between these activities and what this inquiry meant for their teaching practice, we supported this notion of praxis in language teacher education.

Additionally, this study relies on the concept of equity literacy. Gorski (2016) refers to equity literacy as, "...cultivating in teachers the knowledge and skills necessary to become a threat to the existence of inequity in their spheres of influence" (p. 225). Specifically, equity literacy involves recognizing inequity, responding to inequity, redressing inequity, and sustaining equity efforts (Gorski, 2016). We argue that this study of our practice as teacher educators advances the growing body of research equity literacy in practice.

We finally seek to understand how this study can contribute to TESOL teachers' transformational community engagement, which has yet to be studied in great detail. Drawing on conceptions of transformational learning in teacher education, we rethink school "field" experiences, including community engagement, to transform teacher education. This stands in contrast to the notion of simply knowing academic and school knowledge, instead drawing on the assets, strengths, and ways of knowing about students outside-of-school lives and communities (Zeichner, 2010). By transforming community engagement, we encourage candidates to engage in "crossing boundaries" in hybrid spaces. Further, we seek to support teacher candidates in TESOL in a democratic process where who is an "expert" and what types of knowledge count are critically analyzed and questioned (Zeichner, Payne, \& Brayko, 2015), as we support students in the process of becoming TESOL teacher leaders who are engaged in ongoing praxis and reflective practice. We argue that the convergence of these concepts provides a foundation for the formation of an advocacy stance where justice, engagement, and action become essential for teachers' practice.

\section{Methodology}

Utilizing an interpretivist case study (Yin, 2014), recognizing that multiple meanings and realities exist and are informed by our own researcher subjectivity as social justice and equity oriented teacher educators, we focused on the examination of transformative pedagogy for teacher candidates (Pillay, 2015) to improve access and equitable outcomes for EL students. Transformative pedagogy in this case is examined through the analysis of the implementation of and two new assignments, a community asset map and an oral history project, grounded in the theoretical frameworks described above.

\section{Setting and Participants}

At the time of data collection for this study, both authors worked as TESOL program faculty members at a large Southeastern regional comprehensive state university striving towards R2 status. Both faculty members had prior TESOL teaching experience in P-12 and adult education contexts in the United States and abroad and had been working together as TESOL teacher educators for four years. Our university had been the largest producer of P-12 teachers in the state and was regularly lauded for teacher education and community engagement efforts more broadly. Along with a focus on research and community engagement, this institution, as well as the teacher preparation program where we worked had developed numerous online programs and courses. Our M.Ed. TESOL program transitioned into a fully online program over the course of a few years (2013-2015), and we were able to offer a few new courses online, including the course that contextualizes this study-"Collaborative Practices in Schools and Communities." Additionally, as both participants and researchers, we 
recognized our own subjectivities and in order to yield a trustworthy analysis, we reflected on our biases and assumptions as TESOL teachers and teacher educators through individual reflective memos completed during data collection and analysis.

We chose this course for study because it presented a rich case (Yin, 2014) for examining how inservice teachers in an advanced graduate program could transform extant family engagement efforts into theoretically-grounded advocacy. Additionally, we theorized that "field" experiences for online graduate students needed to be thoughtfully examined to be iterative learning experiences for our students (and for ourselves). We selected two of our earliest cohorts of students ( $N=18$ students) for this study as they comprised a purposeful sample (Patton, 1990) for both their geographic locations (with few exceptions these students taught and lived in the nearby counties that comprised both urban and suburban school districts with varying levels of racial, ethnic, and linguistic diversity) and their background knowledges as practicing classroom teachers. Our sample represented teachers across the P-12 continuum and included a variety of content areas, specialists, and teaching responsibilities (e.g. ESOL specialists, secondary content teachers, elementary classroom teachers, grade level leaders). This course, positioned as it was at the end of their graduate programs, was a space for students to draw from their previous course readings, projects and reflective/philosophical writing. There was parity in instruction in both classes, as both teacher educators shared the same online course modules, resources, and syllabus that had been collaboratively created during the course development and instructional design process.

\section{Data Sources and Analysis}

Data sources included M.Ed. candidates' work samples of the community asset map and oral history assignments from two different M.Ed. cohorts (see Appendix B for assignment details), reflective data on the implementation and final products from the assignments, reflective writing completed by the candidates a year later in their capstone courses, and co-constructed memos from both researchers/teacher educators throughout the process. This data collection period covered a two-year time period. While limited in scope, all data sources used in this analysis either directly related to the implementation of the community asset map and oral history assignments or referred back to the influence of these assignments vis-à-vis reflective writing. Despite the limitation of utilizing a bounded data set, we were able to focus on the influence of the implementation of these particular assignments on teachers' understandings. Drawing on our program's theoretical framework explicated above and principles of appreciative inquiry (Cooperrider \& Whitney, 2005), we purposefully worked to add more depth and rigor on the topic of collaboration, broadly defined-moving our assignments with a focus on collaboration from strictly a classroom or teacher-to-teacher activity, to one that included engagement with the broader community both inside and outside the boundary of the school. That is, we wanted to see our candidates transform their pedagogy to include community engagement inside and outside the school walls, and we wanted to re-define, historicize, and challenge those "walls." Further, we wanted teachers to understand what it means to take an asset-based approach to teaching and build bridges with EL students, families, and communities through engagement with new literacy practices (see Russell \& Richey, 2017).

Ultimately, we wanted candidates to understand collaboration within a broader context and as a tool for advocacy. After the course was up and running, we each had the opportunity to teach the course with a cohort of our M.Ed. candidates over the 2015-2016 academic year. Utilizing inductive data 
analysis that is ongoing and iterative, we allowed for the emergence of codes, categories and themes (Glesne, 2006). Inductive data analysis included both researchers coding of the entire data corpus, as well as iterative analysis of primary data samples from both of the assignments under investigation. Codes emerged from both the data set and our theoretical framework (e.g. teacher reflection, pedagogical transformation, community assets, praxis). The findings identified in the analysis of candidate work samples were further triangulated with co-researchers' reflective data (e.g. coresearcher dialogic reflections, co-constructed memos, individual reflective memos). Through iterative data collection, analysis, and triangulation we ensured that our qualitative methods were both trustworthy and reliable by basing interpretations and findings on what emerged from the data corpus (Shenton, 2004).

\section{Community Asset Inquiry Model}

Empirical findings are framed within the context of our proposed model, the Community Asset Inquiry model, that emerged through teacher educator self-study and qualitative data analysis. The Community Asset Inquiry model supports the development of teachers' equity literacy through transformational community engagement. We propose this model to generate an improved understanding of how community assets can be incorporated as critical components of teachers' work as advocates for EL students. As seen in Appendix C, assets and strengths found within communities are at the heart of this model and guide the inquiry. Teachers come to understand that there is a dynamic process in which there is interplay between what resources exist in the community (both social and physical), what the community needs (e.g. recreational spaces, playgrounds), and what the community desires or wants (e.g. accessible parent meetings). The process of understanding the dynamics at play within and around communities and knowing how to draw on these strengths and community desires to positively impact engagement between families and school is what we refer to as Community Asset Inquiry. The process of taking a deep dive into the community, both people and places, facilitates relationships, communication, and deeper connections between teacher, student, social emotional learning and needs, content, and instruction. The notion of who defines community strengths and assets comes from community members themselves and is interpreted through the lens of equity literacy by the teachers themselves. This iterative process of who gets to define community assets supports the process of Community Asset Inquiry. Moreover, the model is further situated within the context of historical and structural issues that comprise community boundaries (e.g. public transportation routes, red-lining, gerrymandering, gentrification, etc.) and these structural constraints are integral to how we refer to the "community."

\section{Findings}

The Community Asset Inquiry model enables us to unpack our findings in ways that illuminate our work as teacher educators engaged in self-study, as well as shed light on how teachers in the M.Ed. TESOL program developed their capacity for praxis as advocates engaged with families and communities. As an online graduate program, assignments were designed to support teachers locally and within the context of where teachers were situated in their teaching and advocacy work. To support teachers as they developed their knowledge and engagement in praxis, embedded scaffolds included engagement with readings, webinars, and video clips. Additionally, teachers watched video clips 
connected to family and community engagement and advocacy. Connected to each of these instructional opportunities, teachers reflected, discussed, and developed a broader repertoire of skills and knowledge.

Work samples were collected across two cohorts and two academic years. The data were analyzed and triangulated along with co-researchers' own reflections. Three main themes related to the development of praxis, equity literacy, and transformative community engagement emerged, with a focus on EL student advocacy spanning across the findings.

\section{(1) From community knowledge to advocacy: Through engagement with families and} community members new ideas about assets and advocacy emerged.

Students in the M.Ed. TESOL program who did not live in the communities in which their schools were located found themselves with limited understandings of the local resources and contours of these communities beyond the geographical. The community asset map and the oral history assignments allowed students to reflect on this prior knowledge and to examine the mismatch between their two worlds and to think about the interstates and roads that connected them. In order to complete the community asset map, graduate students had to bike, walk, and drive inside the community, talking to business owners, looking for spaces where families gathered, and uncovering community resources. Initially, students reported that they were not finding much of interest, instead detailing deficits (such as the lack of green spaces or the existence of chain grocery stores). One student stated:

Living in this community for over 12 years and being married to a Mexican immigrant, I felt like I knew the resources of this community quite well, but my attitude was definitely a deficit perspective. I looked at the visible resources and thought that they were pitiful at best; that we could do better here in the U.S. The soccer fields looked worn, housing was shabby, and I thought most of my students did not have transportation.

For this student, completing the asset map provoked new appreciation and critical reflection on earlier deficit-tinged assumptions about her school community (i.e., "worn" soccer fields, "shabby" housing, etc.). With a new analytic lens developed through engagement with course content and reflection, students cataloged assets and resources as they completed their asset maps and oral histories of a community member, taking special note of how language played a part in representation and access, such as seeing multilingual signage outside community grocery stores or noting a new literacy program for families at a local library. Another student noted:

In the process of creating this community asset map, I had a deficit perspective when I looked around my community. When I started building the list of available resources, I began to realize that Lake Pitzer ${ }^{2}$ was actually very rich in resources.

Noting the issue of power and access, one student provided analytic comments about how immigrant families exercise agency-both in maintaining home culture and seeking out resources in the community that gave them access to power in the larger society. This level of theorizing about the community in a nuanced way provided students with the space to pause and think about how the "local" (in this case,

\footnotetext{
${ }^{2}$ All names and places referenced are pseudonyms.
} 
their school community) is impacted by larger political and economic disparities and how community members resist or attempt to transform their lives. She stated:

The community has challenges, but many assets are available to families. Some assets enable them to maintain their culture, but others help them access the structures in this society, which will give them power.

This comment, profound and telling, reveals the process by which students in this online TESOL program were developing their advocacy stance as they became more grounded in community knowledges and seeming contradictions. Moreover, students were able to think more critically, then articulate more clearly, how geographic and social boundaries were operating in these complex and vibrant contexts.

Furthermore, this finding highlights the connection between engagement with the course assignments and our theoretical Community Asset Inquiry model. As students reflected on completing the community asset map and oral history assignments, they made connections to theory and course readings. As one student wrote in a blog entry:

In addition, in learning of different things in the community I' $m$ able to see the need in the community, which allows me to provide mutual support for parents (Allen, 2007, p.152) and hopefully one day advocate for their families.

Ultimately, as in-service teachers improved their knowledge of the people and communities in which their schools were located, while at the same time participating in theoretical discussions and readings for the course, they were increasingly motivated to take action, or consider what they might do in the future. Through reflective writing and completion of these course assignments, teachers reported an increase in critical and innovative thinking related to assets and advocacy.

\section{(2) Teachers began to make deeper connections between their teaching and advocacy, understanding that as teachers of EL students, the two are inherently connected.}

The M.Ed. TESOL program places a strong emphasis on developing teachers that are strong leaders and advocates for EL students, their families, and communities. Getting to the point where teachers recognize their agency and the connections between teaching and advocacy takes intentionality and requires scaffolding. This scaffolding took place through course design and in the development of assignments that encouraged students to consider their roles as advocates. Through this process, students came to better understand the role of advocacy in their teaching, both for themselves and in their work with families and communities. One teacher reflected on her understanding of advocacy when it came to supporting families in her school:

Our school does a wonderful job advocating for our families and provides resources to help them advocate for themselves. Mrs. Rhodes [Bilingual Parent Liaison] and the entire office staff scaffold the advocacy for parents and students.

This idea that advocacy could be scaffolded for parents and students in this context is a key finding as it sheds light on the inherent responsibility to meet families where they are and to provide them with the tools they need to be successful in navigating the terrain of schools in the U.S. Other teachers had similar 
insights. One teacher noted, "Teachers should work to build relationships with families in order to build their advocacy capacity."

Teachers reflected that as their own capacity for advocacy was being developed, they were also recognizing the need to scaffold and develop the capacity to advocate with their EL students and their families. This, in turn, reflected in their work as teachers in multiple ways. For instance, a teacher described how she approached interactions with families at parent conferences. She stated:

Some parents think they can't help their children because they don't speak English or they don't have internet or money. These are very common explanations that I hear from parents [about lack of involvement]. I always let them know that those things don't matter and give them tips and advice on how they can help their children.

This is a clear example of tangible steps that the teacher was taking to engage with families and provide access to information that they might otherwise not have available. This advocacy work contributed to the families' advocacy capacity. Resultingly, the teacher was able to make connections with families and demonstrate equity literacy (Gorski \& Swalwell, 2015; Gorski, 2014; Gorski, 2016). This teacher empowered families in her sphere of influence to recognize their value and what they bring to the partnership.

Through the Community Asset Inquiry model, it can be deduced that transformational community engagement is afforded by this type of teacher advocacy and leadership work. Specifically, in-service teachers were, ultimately, making connections between seeing the strengths of the community and how they might draw on these assets as advocates for their students, families, and communities with their newfound knowledge and transformative ways of enacting social justice in education (Frederick, Cave, \& Perencevich, 2010).

\section{(3) The use of multimodal literacy practices within an online program supported the development of teachers'skills and knowledge as advocates for EL students.}

Students used an online LMS (Learning Management System) to upload their work and represented their assignments by creating course websites using freely available web 2.0 tools that served as a portfolio of their work. Using multimodal representation with images, text, and hyperlinks allowed students new ways to share and disseminate their findings from both the community asset map and oral history assignments (see Appendix D for an excerpt of a student work sample). For example, the actual practice of building the digital map inspired student insights into the richness of resources and assets in the community. Juxtapositions of multiple assets-including pictures, text, other images, links, etc. - gave a textured view of the communities in which our students worked. This multimodal form of representation is transferable to the $\mathrm{P}-12$ instructional practice, especially applicable for increasingly hybrid and blended learning models. We encouraged students to apply these applications with their own P-12 students and consider how to support students as they discovered the assets and contours of their own communities through participant observation, interviewing, and asset mapping. While we do not have data regarding how or when such assignments have been modified for use with out teachers' $P$ 12 EL students; the hope is that we are modeling effective instruction that has transferability to the P-12 context. Our students relished using new technology, though scaffolding was required to support students successful use of blogs and websites. Using web 2.0 tools such as Google Maps and Weebly 
allowed students to curate their community asset maps and texture their representation in ways that they felt aligned to their understandings of the communities where they worked. One student reflected, This week was full of first [times]. This is my first blog that I will publish in the first website I have ever created, after making a map of resources available in the community where I teach. I am proud and happy to say I might have become [a] savvier teacher that feels like creating a website for her class next.

Building on the experiences of completing these assignments, students reported through reflective writing for the course, as well as in their voluntary final course and program evaluations, that they gained valuable information that would allow them to advocate for their school communities and families and to represent their advocacy more widely-and with more pride.

The opportunity to engage in new literacy practices seems to have opened up the door for students to engage a broader audience and build new perspectives on how they can be impactful as TESOL teachers by allowing students to expand notions of community-both in terms of geographic community and digital/virtual community. With blog, social media and other digital platformsincreasingly places of activism and advocacy for justice-our students acquired new pathways for their work. These are pathways that we hope will be sustained. Through our own reflections, we argue that such assignments in online graduate TESOL programs for practicing teachers that support local and authentic engagement, enable teachers to develop their identities as advocates for social justice and equitable school practices, in particular for their EL students and their families. In this space of cultivating advocacy skills and developing equity literacy, we recognized that students were simultaneously building bridges and dismantling walls-crossing borders and re-imagining well-worn boundaries. In so doing, our students made crucial and relevant connections between home and school. In turn, new spaces for advocacy and educational justice work emerge through digital and online practice.

\section{Discussion and Implications}

Teachers need requisite skills and knowledge in order to engage in praxis, equity literacy, and transformative community engagement as advocates for and with EL students, families, and communities. This knowledge and learning how to advocate for and with EL students, families, and communities need to be acquired (Moll, Amanti, Neff, \& Gonzalez, 1992; Staehr Fenner, 2014). As students become versed in theories and begin to relate the ideas and concepts to their teaching practice, this praxis enables teachers to grapple with issues of equity as they develop their equity literacy (Gorski, 2014). Using the Community Asset Inquiry model to undergird the development of course assignments, enables this praxis to unfold within the context of local school communities that students in an online program are engaging with through their professional roles as teachers. As such, what communities possess, need, and want are illuminated for teachers as they consider their roles as advocate. Online programs that are able to build on praxis in support of advocacy for EL students, families and communities through multimodal literacy practices (Kist, 2005) have the potential to transform the way we engage our candidates in their learning and how they build connections with communities (Russell \& Richey, 2017).

Moreover, the Community Asset Inquiry model has wide-ranging application in a variety of contexts and for a variety of purposes. Supporting pre- and in-service teachers to situate their own 
identities, interrogate their positionalities, develop inquiry/research stances, and explore community assets can be formalized in an assignment or used as a framework for a variety of learning experiences. Additionally, the model could be employed by school-university partnerships, including Professional Development Schools or other collaborative school-university partnerships that focus on issues of equity, access, and advocacy in service of EL students (Russell, 2018). While these assignments were employed in an online course in an online TESOL M.Ed. program, we believe teachers who work in face-to-face contexts would be able to utilize these assignments, perhaps with some modifications. In our own practice with face-to-face courses, we have used these assignments, allowing students who work in the same school community to work in teams and physically joining students as they walk in the community. Representations of this work is not limited to the modalities presented here.

Ultimately, this qualitative self-study inquiry supported our development of the Community Asset Inquiry model that frames our findings and provides teachers and teacher educators with a dynamic tool for supporting the development of equity literacy (Gorski \& Swalwell, 2015) and transforming teacher engagement with school communities to be more authentic and democratic (Zeichner, Payne \& Brayko, 2015). As our schools become increasingly diverse and academic standards swell, the need for teaching that incorporate such practices in support of culturally sustaining pedagogy (Paris, 2012) are becoming more acute. Moreover, there is a persistent need as teacher educators in TESOL to develop ESOL teacher capacity for advocacy, along with the associated community knowledge, equity stance, and understanding of praxis necessary to advocate.

\section{Declaration of Conflicting Interests}

The author declared no potential conflicts of interest with respect to the research, authorship, and/or publication of this article.

\section{Funding}

The authors received no financial support for this research.

\section{ORCID iD}

Felice Atesoglu Russell (iD https://orcid.org/0000-0002-8206-1290

\section{References}

Allen, J. (2007). Creating welcoming schools: A practical guide to home-school partnerships with diverse families. Teachers College Press.

Cooperrider, D. L., \& Whitney, D. (2005). Appreciative inquiry: A positive revolution in change. Berrett-Koehler.

DiGiacomo, D. K., \& Gutiérrez, K. D. (2017). Seven chilis: Making visible the complexities in leveraging cultural repertories of practice in a designed teaching and learning environment. Pedagogies: An International Journal, 12(1), 41-57. https://doi.org/10.1080/1554480X.2017.1283992

Elfers, A. M., Lucero, A., Stritikus, T., \& Knapp, M. S. (2013). Building systems of support for classroom teachers working with English language learners. International Multilingual Research Journal, 7(2), 155-174. https://doi.org/10.1080/19313152.2012.665824 
Epstein, J. L. (2010). School, family, and community partnerships: Preparing educators and improving schools. Westview.

Frederick, R., Cave, A., Perencevich, K. C. (2010). Teacher candidates' transformative thinking on issues of social justice. Teaching and Teacher Education, 26, 315-322.

https://doi.org/10.1016/i.tate.2009.05.004

Gandara, P., Maxwell-Jolly, J., \& Driscoll, A. (2005). Listening to teachers of English Language Learners: A survey of California teachers' challenges, experiences, and professional development needs. Center for the Future of Teaching and Learning.

Garton, S., \& Edge, J. (2012). Why be an online learner in TESOL? In L. England (Ed.), Online language teacher education: TESOL perspectives (pp. 9-21). Routledge. https://doi.org/10.4324/9780203813263

Glesne, C. (2006). Becoming qualitative researchers: An introduction(3rd ed.). Pearson.

Gorski, P. (2014). Imagining an equity pedagogy for students in poverty. In P. Gorski \& J. Landsman (Eds.), The poverty and education reader: A call for equity in many voices. Stylus.

Gorski, P. (2016). Rethinking the role of "culture" in educational equity: From cultural competence to equity literacy. Multicultural Perspectives, 18(4), 221-226. https://doi.org/10.1080/15210960.2016.1228344

Gorski, P., \& Swalwell, K. (2015). Equity literacy for all. Educational Leadership, 72(6), 34-40.

Kist, W. (2005). New literacies in action: Teaching and learning in multiple media. Teachers College Press.

Ladson-Billings, G. (1995). But that's just good teaching! The case for culturally relevant pedagogy. Theory into Practice, 34(3), 159-165. https://doi.org/10.1080/00405849509543675

Lawrence-Lightfoot, S. (2003). The essential conversation: What parents and teachers can learn from each other. Ballantine Books.

Moll, L. C., Amanti, C., Neff, D., \& Gonzalez, N. (1992). Funds of knowledge for teaching: Using qualitative approach to connect homes and classrooms. Theory Into Practice, 31(2), 132-141. https://doi.org/10.1080/00405849209543534

Paris, D. (2012). Culturally sustaining pedagogy: A needed change in stance, terminology, and practice. Educational Researcher, 41(3), 93-97.https://doi.org/10.3102/0013189X12441244

Patton, M. (1990). Qualitative evaluation and research methods $\left(2^{\text {nd }}\right.$ ed.). Sage.

Pillay, A. (2015). Transformative and critical education praxis in a teacher education lecture room. Education as Change, 19(3), 4-23. https://doi.org/10.1080/16823206.2015.1085619

Russell, F.A. (2018). A university and district ESOL coaching partnership: Collaboration within the context of Common Core State Standards implementation. Education and Urban Society, 5O(4), 351-375. https://doi.org/10.1177/0013124517713246

Russell, F.A. \& Richey, A. (2017). Supporting in-service teachers of English learners and their development of an asset-based framework through community asset maps and oral histories in the U.S. In I.H. Amzat (Ed.), Teacher professional knowledge development for reflective and inclusive practices. Routledge. https://doi.org/10.4324/9781315397702-10

Shenton, A. K. (2004). Strategies for ensuring trustworthiness in qualitative research projects. Education for Information, 22(2), 63-75. https://doi.org/10.3233/EFI-2004-22201

Shor, I. (1992). Empowering education: Critical teaching for social change. University of Chicago Press. 
Staehr Fenner, D. (2014). Advocating for English learners: A guide for educators. Corwin.

Yin, R. K. (2014). Case study research: Design and methods $\left(5^{\text {th }}\right.$ ed.). Sage.

Zeichner, K. (2010). Rethinking the connections between campus courses and field experiences in college- and university-based teacher education. Journal of Teacher Education, 61, 89-99. https://doi.org/10.1177/0022487109347671

Zeichner, K., Payne, K. A., \& Brayko, K. (2015). Democratizing teacher education. Journal of Teacher Education, 66(2), 122-135. https://doi.org/10.1177/0022487114560908

\section{Appendix A: M.Ed. TESOL Program Conceptual Framework}

\section{TESOL PROGRAM CONCEPTUAL FRAMEWORK}

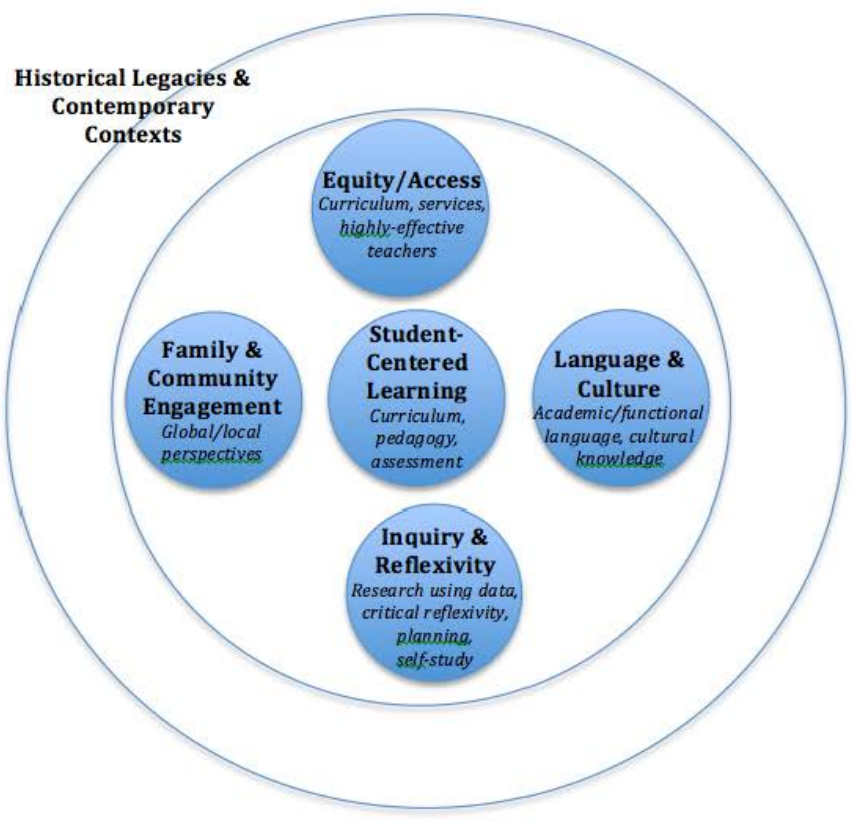

\section{Description}

The MEd, MAT and ESOL Endorsement programs reflect KSU's TESOL Program's Conceptual Framework. The Conceptual Framework includes considerations essential to the personal and academic growth of culturally and linguistically diverse students in P-12 education. With P-12 students as the focus, TESOL Program courses prepare candidates' knowledge and dispositions around issues of equity and access, language and culture, family and commun ity engagement, and inquiry and reflexivity. Understanding that influences outside the class room and school impact the education of culturally and linguistically diverse learners, these is sues are examined with in the historical legacies and contem porary contexts of education as a whole.

\section{Components}

Historical Legacies and Contemporary Contexts - the Backdrop In this program we exam ine how historical legacies and contem porary policy contexts converge on the institution of schooling and the individuals inside them. We believe that teaching, learning, and going to school are sociohistorically constituted activities (McDermott \& Varen ne, 1995) set within figured worlds (Holland et al, 1998). The figured worlds that candidates teach and work in are made possible by shared discourses, cultural artifacts, object, and symbols inscribed and sanctioned over time through collective attribution of meaning. We adopt a critical lens, language, and methods to guide our candidates toward identifying and challenging historical and current legacies (Willinsky, 1998) in teaching practices, curricular materials, and education reform efforts for culturally and linguistically diverse learners. 


\section{Student-Centered Learning}

Student-centered learning occurs when the learning process is negotiated through the leadership of the teacher and allows for the mutual sharing of authority by teacher and students. It is not merely project based learning where the teacher acts as a guide, includes technology in classroom teaching and assignments, or allows for student choice. Rather in a student-centered classroom, the teacher and students strive to transform traditional approaches to learning into ones that are critical and democratic (Shor, 1992). The hallmarks of student-centered learning include: creativity, inventiveness, resiliency, critical thinking, problem solving, collaboration, effective communication, empathy and multiple literacies (Zmuda, 2010). Students and teachers are actively engaged in constructing meaning of what is being studied; learning is relevant to students' lives, both current and future; higher levels of critical thinking are the norm; self-reliance is encouraged; and instruction is differentiated for language development level, literacy level, ability, interest, and relevance in order to provide students entry points into subject areas so that they can make informed choices about future learning.

\section{Equity \& Access}

Equity and access are cornerstones of a quality education for children learning English as an additional language. The Supreme Course case Lau v. Nichols established that equity was not achieved merely by providing learners of English with the same facilities, textbooks, teachers and curriculum as their English-proficient peers (Lau v. Nichols, 1974). Critical equity issues include 1) education programs that meet students' socio-emotional, cultural, linguistic and academic needs; 2) fair, appropriate, valid and reliable assessment; 3) appropriate resources; and 4) parental and community involvement in the educational process (García, Kleifgen, and Falchi, 2008.) Equity includes access to structures within schools such as cognitively and linguistically-rich curricula and access to categorical programs such as special education, speech, extracurricular activities and clubs. Language should never be a barrier to participation in social and academic structures within schools

Recognizing the essential nature of teacher experience, content knowledge, pedagogical skills, attitudes, and behaviors for student success, we provide coursework and field placement experiences that develop a deep knowledge and actualization of instructional practices and advocacy based on equity and access for English learners in P-12 contexts.

\section{Language \& Culture}

Language and culture frames our understanding of student-centered learning. The two are inextricably linked.

Conceptions of language takes into account both first and second language acquisition and development. We understand language development in classrooms as a sociocultural process (Donato, 2000) that is linked to identify formation and development and influenced by the context in which language learning and negotiation takes place (Morita, 2004). In particular, awareness of language is understood through sociopolitical contexts in which the language learning is taking place and deeply connected to student learning through teacher preparation that develops pedagogical language knowledge (Bunch, 2013). We draw from such areas as first and second language acquisition, linguistics, and frame these concepts with a focus on teaching and learning in P-12 contexts.

Through a reflexive multicultural approach (Asher, 2007) candidates will examine how historical legacies converge upon their own identities and epistemologies and the lives of their students. Candidates will learn how to implement culturally sustaining pedagogy (Paris 2012) where cultural identity breaks out of the narrow confines of ethnicity, and is imagined dynamically beyond territory and national borders (Lukose 2007). 


\section{Appendix B: Community Asset Map and Oral History Assignment}

\section{Engaging with the Community: Asset Map and Oral History Project of Community Member}

*These assignments should either inform or connect to your Advocacy Project

\section{Part I: Community Asset Map ( 30 points)}

Individually or in small teams, students will complete a community asset map in a community of choice (typically where one is engaged in teaching). Employing the methodology of appreciative inquiry ${ }^{1}$, including visits to the field, students will construct a visual model of the assets of a community and present their findings to the class via Weebly. A summative narrative is required.

1. Decide on the community boundary that you will focus on based upon where your students spend time before and after school (where they live, after-school programs they attend, places of worship, etc.).

- Drive, walk, and/or bike around parts of the community. Get out of your car and stop by the local market, restaurants, and stores; visit after-school programs and places of worship; walk around the local parks and playgrounds; and visit the neighborhoods and apartment complexes. Feel free to take pictures as appropriate. Engage with people at the various locations.

- Do some research on this particular community before and after your field visit(s) on the types of business and community resources available. Pick 3-5 community assets for emerging bilingual learners and their families that you found that are of interest and find out more in-depth information about them.

2. Create a map using Google maps, another mapping program of your choice, another tech tool, or paper (you will need to photograph or scan your work so you can upload to Weebly). Embed those assets that are of particular importance to the community (however, include at least 10 assets).

- Locate and label the asset on your community map

- Include a description of what is it and why it is important to the community

- Upload your map and any pictures you would like to include to your Weebly site

1 “'[Appr eciative Inquir y] deliberately seeks to discover people's exceptionality - their unique gifts, strengths, and qualities. It actively searches and recognizes people for their specialties - their essential contributions and achievements. And it is based on principles of equality of voice - everyone is asked to speak about their vision of the true, the good, and the possible. Appreciative Inquiry builds momentum and success because it believes in people. It really is an invitation to a positive revolution. Its goal is to discover in all human beings the exceptional and the essential. Its goal is to create organizations that are in full voice!"

Cooperrider, D.L. et. al. (Eds) , Lessons from the Field: Applying Appreciative Inquiry, Thin Book Publishing, 2001, page 12 .

See also Using Appreciateive Inquiry in Educational Research: Possibilities and Limitations (Shuayb, Sharp, Judkins, and Hetherington, 2009)

3. Write and include a summative findings narrative (think $\sim 2$ pages, double-spaced max text) on your Weebly site. Discuss the following:

- Assets available to the school community

- How you might be able to utilize the 3-5 assets for emerging bilingual learners and their families (i.e. in your teaching or advocacy project).

- Any particular successes or challenges you had in completing this project

- Connections to course resources using APA format (at least 2) 


\section{Part II: Oral History Project: Community Interview (50 points)}

Students will complete an oral history project that centers on listening to families and communities in order to understand the history, context, and range of assets available in the particular school community. Identification of community members (can come from inside or outside the school) for the oral history will be facilitated by instructor and informed by community asset mapping field visits. Select an individual that is both willing to be interviewed and makes for a good case study. Ethical considerations, connection to schooling, and proposed advocacy project must be considered.

1) Develop a structured or semi-structured interview protocol with about 5-10 questions based on knowledge of the community, community member, and course / TESOL program readings
Sample Questions:
How did you come to live and/or work in this community?
What makes this community unique? (Follow-up: What are some events that bring the community together over the year?)
In what ways have you, or would you like to, engage with $\mathrm{X}$ school?
How does your organization support $\mathrm{X}$ school and the families in this community?
What is your relationship to X school? (Follow-up: Have you in the past or do you currently have family members that attend $X$ school? What does the community think of X school? )
${ }^{*}$ Note: Make your questions unique to your particular participant and context.

2) Conduct $\sim 20$ minute interview with the community member and digitally record (be sure the participant is okay with recording). You may record using whatever recording device you have available.

3) Write-up your findings and post to your Weebly site. (500-800 words)

4) In your write-up highlight critical findings, research-infused reflection from the oral interview, and any salient direct quotes from the recorded interview that help to support your main points.

\section{Engaging with the Community: Asset Map and Oral History Project Rubrics}

\begin{tabular}{|c|c|c|c|c|c|}
\hline $\begin{array}{l}\text { Components } \\
\text { Asset Map Possible Pts (30) } \\
\text { Oral History Possible Pts (50) }\end{array}$ & $\begin{array}{c}\text { Unacceptable (F) } \\
18-20 \\
30-34\end{array}$ & $\begin{array}{l}\text { Reaching (C) } \\
21-23 \\
35-39\end{array}$ & $\begin{array}{l}\text { Good (B) } \\
24-26 \\
40-44\end{array}$ & $\begin{array}{l}\text { Excellent (A) } \\
27-30 \\
45-50\end{array}$ & Score and Feedback \\
\hline Purpose/Audience & $\begin{array}{l}\text { Purpose unclear, } \\
\text { failure to address topic } \\
\text { or directions. }\end{array}$ & $\begin{array}{l}\text { Wavers in purpose, } \\
\text { incompletely addresses topic } \\
\text { or directions. }\end{array}$ & $\begin{array}{l}\text { Adheres to purpose, fulfills } \\
\text { all components of the } \\
\text { assignment, shows } \\
\text { understanding of key issues. }\end{array}$ & $\begin{array}{l}\text { Addresses purpose effectively, } \\
\text { fulfills all components of the } \\
\text { assignment, shows full } \\
\text { understanding of issues, engages } \\
\text { audiences. }\end{array}$ & \\
\hline Documentation/Support & $\begin{array}{l}\text { Most ideas } \\
\text { unsupported, } \\
\text { confusion between } \\
\text { subjective (experience) } \\
\text { and abjective } \\
\text { (readings) evidence, } \\
\text { reasoning flawed. }\end{array}$ & $\begin{array}{l}\text { Presents ideas in general } \\
\text { terms, support for ideas is } \\
\text { inconsistent across su bjective } \\
\text { and objective evidence; need } \\
\text { clarification, reasoning } \\
\text { unclear. }\end{array}$ & $\begin{array}{l}\text { Supports most ideas with } \\
\text { effective examples and } \\
\text { details, suitable balance } \\
\text { between references to } \\
\text { subjective and objective } \\
\text { evidence. }\end{array}$ & $\begin{array}{l}\text { Explores ideas critically, supports } \\
\text { points using an appropriate } \\
\text { balance of subjective and objective } \\
\text { evidence. }\end{array}$ & \\
\hline Analysis & $\begin{array}{l}\text { Weak grasp of issues, } \\
\text { no connections to } \\
\text { concepts or readings } \\
\text { discussed in class. }\end{array}$ & $\begin{array}{l}\text { Demonstrates understanding } \\
\text { of issues but connections to } \\
\text { concepts or readings are } \\
\text { reaching or inconsistent. }\end{array}$ & $\begin{array}{l}\text { Understand issues and uses } \\
\text { the concepts and readings } \\
\text { to extend analysis. }\end{array}$ & $\begin{array}{l}\text { Demonstrates mastery of issue } \\
\text { and uses the concepts and } \\
\text { readings to extend analysis. }\end{array}$ & \\
\hline Mechanics and Presentation & $\begin{array}{l}\text { Unorganized and } \\
\text { difficult to follow, } \\
\text { inappropriate style. } \\
\text { Does not follow APA } \\
\text { conventions. }\end{array}$ & $\begin{array}{l}\text { Sentence structures are } \\
\text { adequate to convey basic } \\
\text { meaning, errors cause } \\
\text { noticeable distraction. Does not } \\
\text { follow APA conventions. }\end{array}$ & $\begin{array}{l}\text { Sentence structure is } \\
\text { effective, presence of a few } \\
\text { errors is not distracting. } \\
\text { Follows APA conventions } \\
\text { with a few mistakes. }\end{array}$ & $\begin{array}{l}\text { Sentence structure is effective. } \\
\text { There are no errors; Follows APA } \\
\text { conventions correctly. }\end{array}$ & \\
\hline
\end{tabular}




\section{Appendix C: Community Asset Inquiry Model}

Structural issues that comprise "community" boundaries

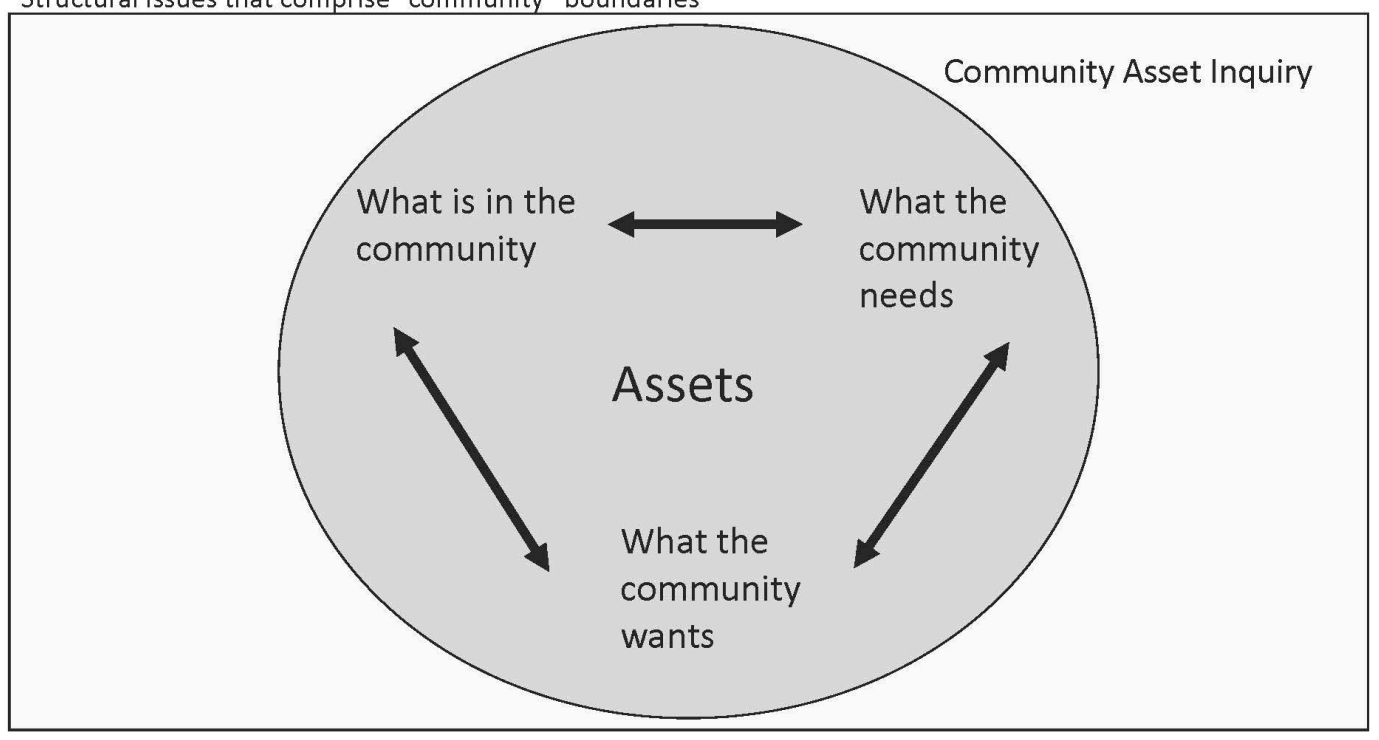

Community Asset Inquiry model. A dynamic model of teacher inquiry for transformational community engagement.

\section{Appendix D: Student Work Sample}

Community Asset Map - Collaborative Practices with Families, Schools, and Communities

\section{COLLABORATIVE PRACTICES WITH FAMILIES, SCHOOLS, AND COMMUNITIES}

\footnotetext{
\begin{tabular}{l|l|l} 
RESOURCES FOR COLLABORATION BLOG PROFESSIONAL COMMUNICATION PLAN & COMMUNITY ASSET MAP
\end{tabular}

ORAL HISTORY PROJECT: COMMUNITY INTERVIEW ADVOCACY PROJECT
}

THE COMMUNITY OF

ELEMENTARY SCHOOL

Community History

Elementary School is located in

The school hosts a majority Latino/a population, and $99 \%$ of the students receive free or reduced lunch. A dramatic population shift occurred in the area about 10-15 years ago, as Latino families moved into formerly white working-class neigh borhoods. The graph I created shows this population shift.

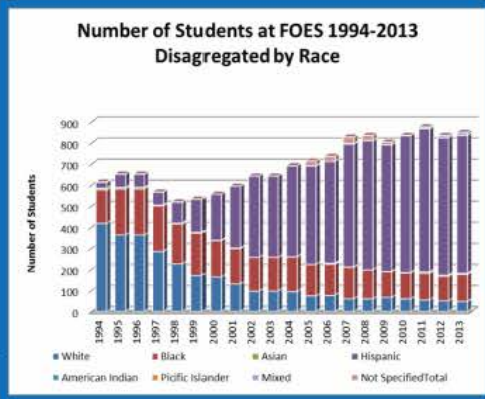


Deficit thinking predominates views of the housing ranges from single-family homes, which are older and in various states of repair, to

Elementary School attendance zone. Available apartment complexes with small apartments, and trailer parks that demonstrate extreme noverty. I am aware of the challenges facing the families living in this area since I teach at daily struggles of students and their families have become obvious.
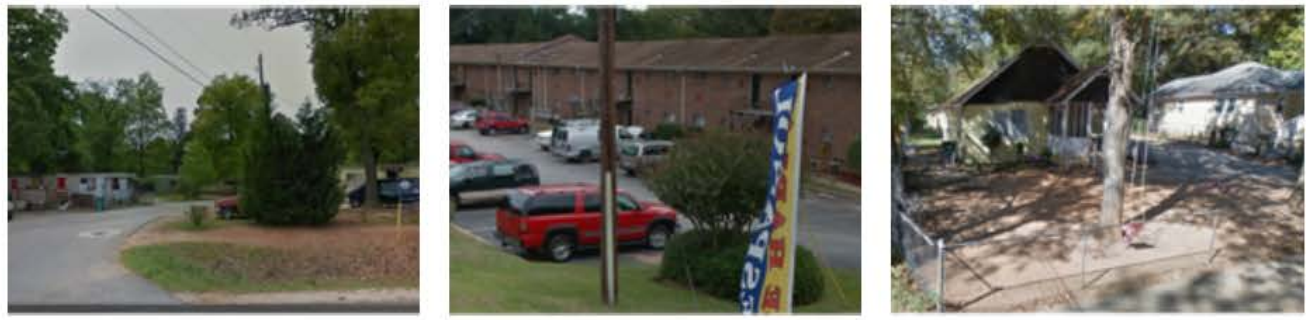

\section{ASSETS MAP}

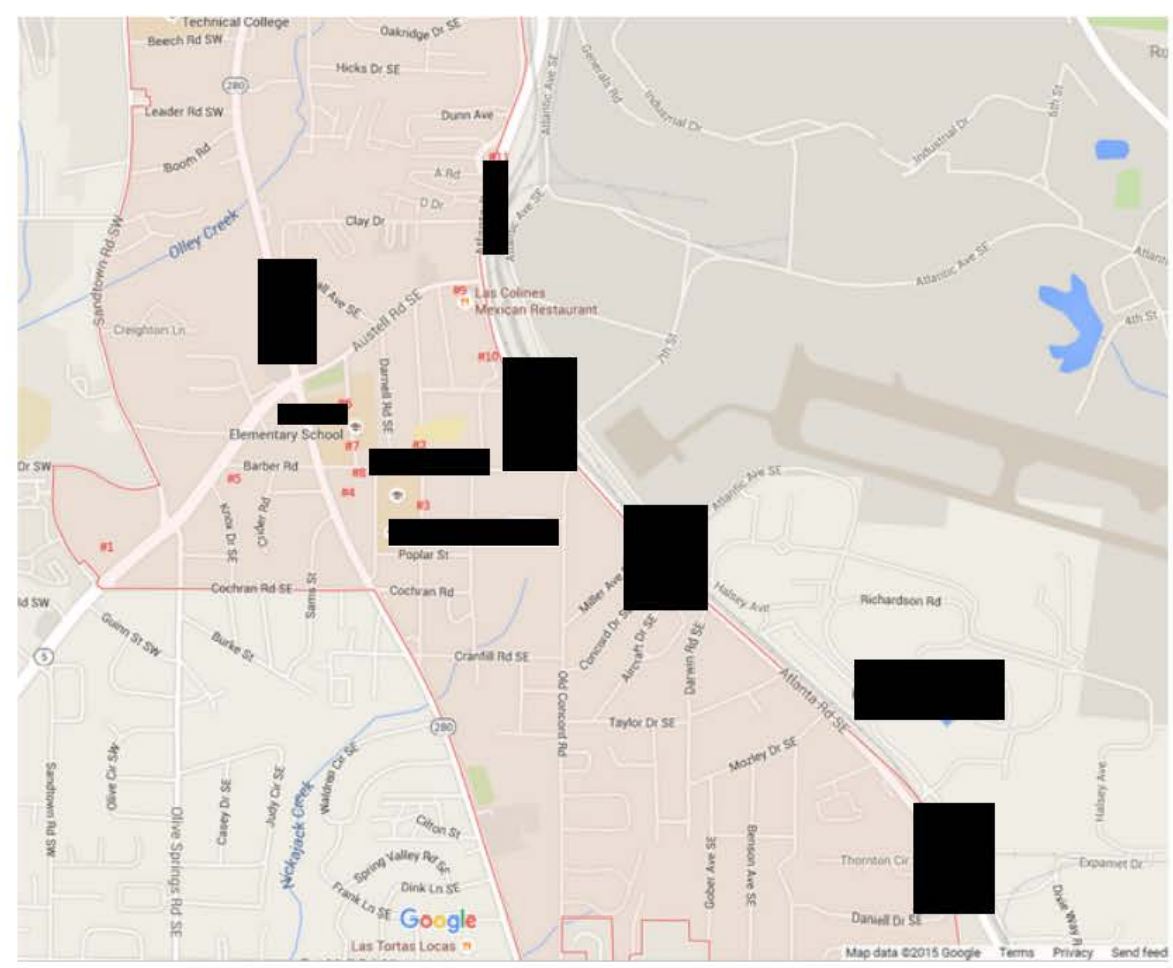

The community has challenges, but many assets are available to families. Some assets enable them to maint ain their culture, but others help them access the structures in this society, which will give them power. I have numbered the map with 11 assets; each has a picture and brief description. 